\title{
Habitat Amount, Habitat Heterogeneity, and Their Effects on Arthropod Species Diversity
}

Author(s): Bruno Travassos-De-Britto \& Pedro Luís Bernardo da Rocha

Source: Ecoscience, 20(3):207-214. 2013.

Published By: Centre d'études nordiques, Université Laval

DOI: http://dx.doi.org/10.2980/20-3-3606

URL: http://www.bioone.org/doi/full/10.2980/20-3-3606

BioOne (www.bioone.org) is a nonprofit, online aggregation of core research in the biological, ecological, and environmental sciences. BioOne provides a sustainable online platform for over 170 journals and books published by nonprofit societies, associations, museums, institutions, and presses.

Your use of this PDF, the BioOne Web site, and all posted and associated content indicates your acceptance of BioOne's Terms of Use, available at www.bioone.org/page/terms_of_use.

Usage of BioOne content is strictly limited to personal, educational, and non-commercial use. Commercial inquiries or rights and permissions requests should be directed to the individual publisher as copyright holder. 


\title{
Habitat amount, habitat heterogeneity, and their effects on arthropod species diversity ${ }^{1}$
}

\author{
Bruno TRAVASSOS-DE-BRITTO² \& Pedro Luís Bernardo da ROCHA, Universidade Federal da Bahia, \\ Instituto de Biologia, Rua Barão de Jeremoabo, 40.170-115, Salvador-BA, Brasil, e-mail: bruno.travassos@gmail.com
}

\begin{abstract}
Not all studies have empirically supported the model that predicts a positive relationship between habitat heterogeneity and biodiversity. We hypothesized that these different results stem from the methods used to assess habitat heterogeneity; many studies used variables that are somewhat correlated in nature and measure 2 different features of the environment: a) the number of structure types (habitat heterogeneity) and b) the number of structures, disregarding their types (habitat amount). We tested this hypothesis with a single experiment that assigned orthogonal values of habitat heterogeneity and habitat amount to artificial environments located on the floor of a forest remnant. We statistically controlled the number of individuals in each environment to prevent a random sample effect. We used the number of arthropod morphospecies present in the environments after $60 \mathrm{~d}$ as our dependent variable. The results indicate that habitat heterogeneity had no significant effect on species richness, while habitat amount showed a positive effect when the number of individuals was not controlled. Neither habitat heterogeneity nor habitat amount affected species richness when the number of individuals was controlled. We conclude that conflicting results in previous tests of the heterogeneity model could stem from conceptual and methodological problems in experimental conception. We suggest that further studies distinguish between heterogeneity and area effects, design proper controls for different effects, and consider the spatial scale of the ecological processes that influence species diversity.
\end{abstract}

Keywords: Atlantic Rainforest, complexity measurements, habitat complexity hypothesis, spatial heterogeneity.

Résumé: Les résultats empiriques de diverses études n'appuient pas tous le modèle qui prédit une relation positive entre l'hétérogénéité de l'habitat et la biodiversité. Nous formulons l'hypothèse que ce sont les méthodes utilisées pour évaluer l'hétérogénéité de l'habitat qui sont responsables de ces différents résultats; plusieurs études utilisent des variables qui sont en partie corrélées et mesurent ainsi deux caractéristiques distinctes de l'habitat naturel: a) le gradient du nombre de types de structure (hétérogénéité de l'habitat) et b) le gradient du nombre de structures de tous types confondus (nombre d'habitats). Nous avons testé cette hypothèse en une seule expérience en attribuant des valeurs orthogonales d'hétérogénéité de l'habitat et de nombre d'habitats à des environnements artificiels placés au sol dans une parcelle forestière. Dans les analyses statistiques, nous avons contrôlé pour le nombre d'individus dans chaque environnement afin d'éliminer un effet de répartition aléatoire. Nous avons utilisé comme variable dépendante le nombre d'espèces morphologiques d'arthropodes présents dans les environnements après 60 jours. Les résultats indiquent que l'hétérogénéité de l'habitat n'avait pas d'effet significatif sur la richesse en espèces, tandis que le nombre d'habitats montrait un effet positif seulement lorsque le nombre d'individus n'était pas été contrôlé. Ni l'hétérogénéité de l'habitat ni le nombre d'habitats n'avaient d'effet sur la richesse en espèces lorsque le nombre d'individus était contrôlé. Nous concluons que les résultats contradictoires des études précédentes sur le modèle d'hétérogénéité pourraient avoir été causés par des problèmes conceptuels et méthodologiques des expériences. Nous suggérons pour les futures études d'inclure une distinction entre l'hétérogénéité et les effets de superficie, de prévoir des contrôles appropriés pour les différents effets et de prendre en considération l'échelle spatiale des processus écologiques qui influencent la diversité des espèces.

Mots-clés: forêt tropicale humide atlantique, hétérogénéité spatiale, hypothèse de la complexité de l'habitat, mesures de complexité.

\section{Introduction}

Research over several decades has identified environmental heterogeneity as a cause of species distribution gradients in nature (Pianka, 1966; Huston, 1979; Lassau et al., 2005; Sirami et al., 2008). MacArthur and MacArthur (1961) were the first authors to empirically test the effects of habitat heterogeneity on species diversity. These authors concluded that a more heterogeneous habitat can support more species. The primary argument to explain this finding and the subsequent results (e.g., Simpson, 1964;

${ }^{1}$ Rec. 2013-03-04; acc. 2013-07-30.

Associate Editor: Zoe Lindo.

${ }^{2}$ Author for correspondence.

DOI 10.2980/20-3-3606
Pianka, 1966; Murdoc, Evans \& Peterson, 1972) was that a heterogeneous habitat has more diverse structural arrangements that provide more niche dimensions (Kadmon \& Allouche, 2007). Consequently, such habitats might support the coexistence of a higher number of species. However, not all of the empirical data from studies of heterogeneity and biodiversity support these predictions (e.g., August, 1983; Feller \& Mathis, 1997; Brose, 2003; Lassau \& Hochuli, 2004; Lassau et al., 2005).

The utilization of different methods to measure environmental heterogeneity (Kolasa \& Pickett, 1991; Sparrow, 1999) might explain the conflicting results, but this topic has received little attention compared to other 
methodological issues (Tews et al., 2004). The literature has used 2 quite distinct structural variables to assess habitat heterogeneity, even though the measurement of different habitat features could influence biodiversity assessments (Heck \& Wetstone, 1977). The first method considers the number of different types of structures in the habitat (e.g., MacArthur \& MacArthur, 1961; August, 1983; BöhningGaese, 1997; Atauri \& Lucio, 2001; Brose, 2003; Lassau \& Hochuli, 2004; Lassau et al., 2005; Randlkofer et al., 2010), and the second method considers the simple number of structures, regardless of type (e.g., Vivian-Smith, 1997; Ceballos, Pacheco \& List, 1999; Halaj, Ross \& Moldenke, 2000; Schiegg, 2000).

Although all these authors used a model of heterogeneity in their arguments, the authors who merely used the number of structures to measure heterogeneity seem to have measured a feature of the environment that reflects habitat amount rather than habitat heterogeneity (Heck \& Wetstone, 1977; Ceballos, Pacheco \& List, 1999; Halaj, Ross \& Moldenke, 2000; Schiegg, 2000). The addition of a new type of structure in the environment provides a new dimension of niche (MacArthur \& MacArthur, 1961), but the addition of a structure identical to the existing structures only increases the amount of suitable habitat and fails to provide a new niche dimension.

The effect of habitat amount on species richness is one of the most studied phenomena in ecology (see Báldi, 2008), and proposed explanations for this relationship include statistical models that suggest a habitat with a larger area contains more individuals and therefore more species (random placement hypothesis) (Connor \& McCoy, 1979; Whittaker, 1998). Mechanistic models state that an area increase potentially increases the population size and reduces the risk of extinction (area per se hypothesis) (Preston, 1960; MacArthur \& Wilson, 1967; Kallimanis et al., 2008). The dynamic equilibrium between immigration and extinction rates models (theory of island biogeography) (MacArthur \& Wilson, 1967; McGuinness, 1984; Whittaker, 1998) frequently indicates that area increases affect habitat heterogeneity and therefore species richness (habitat heterogeneity model: Rosenzweig, 1995; Tews et al., 2004; Báldi, 2008; Kallimanis et al., 2008).

The measures of heterogeneity used to test the heterogeneity model are typically positively correlated in nature (MacArthur \& Wilson, 1967; Kohn \& Walsh, 1994; Rosenzweig, 1995; Kallimanis et al., 2008). These measures may compound their effects on species richness (Mac Nally \& Watson, 1997). Studies that independently evaluated each of the factors (see references in Kallimanis et al., 2008) or specifically attempted to disentangle the effects of habitat amount and habitat heterogeneity on species richness produced conflicting results that detected the dominant effect on species diversity of the area (Nilsson, Bengtsson \& As, 1988; Thomas et al., 2001), heterogeneity (Myklestad \& Saetersdal, 2004; Báldi, 2008; Jonsson, Yeates \& Wardle, 2009), or both (Ricklefs \& Lovette, 1999; Pysek, Kucera \& Jarosik, 2002; Kallimanis et al., 2008; Marini et al., 2010), even for different taxa in the same study (Báldi, 2008).

Kallimanis et al. (2008) suggested that scale could be an important factor that mediates the results of the partial influence of habitat amount and habitat heterogeneity on species richness. For fine spatial scales, the authors argue that the effect of habitat amount is dependent on the abundance of individuals (as explained by the random placement hypothesis). For larger spatial scales, the effect of area is related to increases and decreases in population extinction risk, as described in the area per se hypothesis, in which the abundance of individuals plays a minor role. These 2 hypotheses use distinct mechanisms to explain the effect of habitat amount on species richness, and the relative contribution of the 2 effects may change with scale.

Mensurative studies have evaluated the partial effect of habitat heterogeneity and habitat amount with coarse spatial scales in systems in which these 2 variables are not positively correlated (Báldi, 2008; Kallimanis et al., 2008), and other studies have used statistical procedures to consider partial effects (Kohn \& Walsh, 1994; Marini et al., 2010). We developed a single manipulative experiment to evaluate whether habitat amount and habitat heterogeneity differentially affect species richness at a fine spatial scale. We statistically remove the abundance effect of sampled individuals, which is known to affect richness estimation (random placement hypothesis). This experiment evaluates which hypothesis better explains the variation in species richness at this scale and tests whether these different measures of heterogeneity exert different effects on species richness measures.

To measure diversity, we selected species richness, which we consider to be the most direct measure of diversity affected by heterogeneity based on the classical model of heterogeneity (MacArthur \& MacArthur, 1961; Simpson, 1964; Pianka, 1966; Murdoc, Evans \& Peterson, 1972). The rationale for the notion that a more heterogeneous habitat sustains a greater diversity of species is that an increase in heterogeneity adds a new dimension of niche (Kadmon \& Allouche, 2007). The concept of niche is closely attached to the concept of species (see Whittaker, Levin \& Root, 1973). It is reasonable to suggest that a change in some dimensions of niche caused by a change in heterogeneity would change the probability of habitat colonization by a new species and directly alter species richness. This experiment evaluates arthropods for their sensitivity to small-scale changes in structure (Robinson, 1981; Antvogel \& Bonn, 2001; Lassau \& Hochuli, 2004; Blaum et al., 2009; González-Megías, Gómez \& Sánchez-Piñero, 2011) and the speed with which they colonize newly formed habitats (Edwards \& Thornton, 2001; Bess et al., 2002; Brose, 2003).

\section{Methods}

\section{THE EXPERIMENT}

We designed a manipulative experiment in which habitat amount and habitat heterogeneity were independently assigned to 20 artificial environments. The environments were left on the forest floor for arthropods.

Each artificial environment consisted of a 1- $\times 1-\mathrm{m}$ white plastic sheet stretched across the forest floor. We affixed a certain number of structures to determine habitat amount and habitat heterogeneity. Each structure consisted of a 10- $\times 10-\times 7-\mathrm{cm}$ plastic box opened along the 
lateral faces. These structures, which served as shelters, contained different types of inner substrates. Nineteen different types of substrates were used to fill the structures (Table I). We standardized the quantity of substrate material in different boxes so that the structures with the same type of substrate were virtually identical. Many studies have successfully used artificial structures for arthropod colonization and shelter (e.g., Robinson, 1981; Gürtler et al., 2001; Bowie et al., 2006), indicating that these organisms can utilize an artificial habitat that emulates certain characteristics of their natural habitat. In our experiment, we endeavoured to select substrates that structurally reflect the substrates found in forest soil, and we considered aspects that are relevant to arthropods, including the orientation of sticks and twine (Robinson, 1981), the irregularity and different types of shelter caused by the disposition of pebbles, leaves, and pieces of tree bark with concave surfaces (Kaspari \& Weiser, 1999), and the effects of roots and vines of different thicknesses (Blaum et al., 2009). We used only industrialized or sterilized material to avoid uncontrolled chemical luring and the addition of arthropods prior to the experiment.

We mounted all 20 artificial environments on the forest floor in a 13- $\times 10-\mathrm{m}$ grid. The edges of each artificial environment were $2 \mathrm{~m}$ away from the edges of the 4 neighbouring environments. A random number of boxes between 21 and 40 were placed in each artificial environment to set the habitat amount. Only the arthropods in these boxes were collected, so the number of boxes corresponded to the amount of suitable habitat in one environment. Each of the boxes contained 1 type of substrate, but more than 1 type could be present in a single habitat; habitats with more types of substrate had greater heterogeneity. To set the habitat heterogeneity independently of the habitat amount in an environment, we selected a random number between 1 and 19. This number determined the number of types of substrate in this environment (Table II). Each artificial environment ultimately had independent values for habitat amount (number of boxes) and habitat heterogeneity (number of types of substrate) (Figure 1).
We left the artificial environments on the forest floor for $60 \mathrm{~d}$ during the rainy season (17 June to 15 August 2010). This time period is 1 order of magnitude higher than the $8 \mathrm{~d}$ considered adequate for spider colonization in a temperate forest (see Robinson, 1981). Although this time period is greater than necessary for passive arthropod sampling (e.g., Longino, 1994; Holland \& Smith, 1999; Kitching, Li \& Stork, 2001; Work et al., 2002), our experiment did not use any type of trapping or luring system. The experiment was designed to allow the arthropods to walk freely and stay inside the structure if it was a useful resource for them. We expected to find a much lower number of individuals in the artificial environments compared to a trapping survey. However, this methodology should not pose a problem because surveying arthropod diversity in the fragment was not the purpose of this study.

After $60 \mathrm{~d}$, we removed the boxes from the plastic sheet, individually packed each box with its dwellers inside, and took the boxes to the lab. There, we unpacked the boxes and hand collected all arthropods larger than $1 \mathrm{~mm}$ with the aid of an illuminated magnifying glass and tweezers. The arthropods were preserved in $70 \%$ alcohol for identification.

We used identification keys to identify each specimen to order (Gibb \& Oseto, 2006) and identified the morphospecies in each order. We sent all Araneae individuals for independent identification by a taxonomist specializing in this taxon (A. Brescovitch, Butantan Institute, São Paulo, Brazil) to calibrate the effect of identification by a non-specialist.

The identifications of the spider species by the specialist (14 species) almost coincided with the morphospecies identifications by the non-specialist (15 morphospecies), indicating that our identifications were well calibrated with those of the specialist. The literature indicates that utilizing morphospecies as the level of taxonomic resolution is an efficient method of surveying arthropod biodiversity (Oliver \& Beattie, 1996a,b; Pik, Oliver \& Beattie, 1999; Derraik et al., 2002; Schnell, Pik \& Dangerfield, 2003). Therefore, our study can be compared with studies of both morphospecies and taxonomic species.

TABLE I. Different types of substrates used to create habitat heterogeneity. The description of each substrate specifies how these substrates are installed in the boxes to form structurally different objects that create the environment.

\begin{tabular}{|c|c|c|}
\hline Substrate number & Types of substrates & Description \\
\hline 1 & Sisal twine tangled around the box & Forming 4 horizontal vectors \\
\hline 2 & Shredded sisal & $10 \mathrm{~g}$ \\
\hline 3 & Clay & $20 \mathrm{ml}$, grain $<1 \mathrm{~mm}$ diameter \\
\hline 4 & Clay & $20 \mathrm{ml}$, grain between 1 and $15 \mathrm{~mm}$ \\
\hline 5 & White sand & $20 \mathrm{ml}$ \\
\hline 6 & Wooden sticks & 7 horizontal vectors with $2 \mathrm{~mm}$ diameter \\
\hline 7 & Wooden sticks & 9 vertical vectors with $2 \mathrm{~mm}$ diameter \\
\hline 8 & Chopped wooden stick & 30 pieces with $4 \mathrm{~cm}$ long with $2 \mathrm{~mm}$ diameter \\
\hline 9 & Cotton twine chopped & 70 pieces with $3 \mathrm{~cm}$ length \\
\hline 10 & Cotton twine tangled around the box & Forming 8 vertical vectors \\
\hline 11 & Synthetic polyester cotton & $5 \mathrm{~g}$ \\
\hline 12 & Shavings & $10 \mathrm{~g}$ \\
\hline 13 & Plastic caps & 6 unities with $2.5 \mathrm{~cm}$ diameter \\
\hline 14 & Gravel & 6 units $<6 \mathrm{~cm}$ diameter \\
\hline 15 & Pieces of hard undulate plastic & 10 pieces with $2 \times 3 \mathrm{~cm}$ \\
\hline 16 & Styrofoam platforms & 2 horizontal platforms spaced $2 \mathrm{~cm}$ \\
\hline 17 & Styrofoam platforms & 4 vertical platforms spaced $2 \mathrm{~cm}$ \\
\hline 18 & Styrofoam semi-spheres & 6 units with $3 \mathrm{~cm}$ diameter \\
\hline 19 & Pebbles & 6 units $<6 \mathrm{~cm}$ diameter \\
\hline
\end{tabular}


TABLE II. Abundance and richness of arthropods observed in each artificial habitat with its respective values for heterogeneity and habitat amount.

\begin{tabular}{ccccc}
\hline \hline $\begin{array}{c}\text { Sample } \\
\text { unit }\end{array}$ & $\begin{array}{c}\text { Habitat } \\
\text { heterogeneity }\end{array}$ & $\begin{array}{c}\text { Habitat } \\
\text { amount }\end{array}$ & $\begin{array}{c}\text { Individuals } \\
\text { abundance }\end{array}$ & $\begin{array}{c}\text { Arthropods } \\
\text { richness }\end{array}$ \\
\hline 1 & 18 & 25 & 54 & 20 \\
2 & 2 & 34 & 59 & 19 \\
3 & 15 & 21 & 37 & 9 \\
4 & 11 & 19 & 27 & 7 \\
5 & 15 & 22 & 24 & 7 \\
6 & 14 & 35 & 48 & 15 \\
7 & 5 & 31 & 16 & 9 \\
8 & 12 & 27 & 14 & 8 \\
9 & 13 & 33 & 30 & 12 \\
10 & 14 & 16 & 33 & 14 \\
11 & 2 & 19 & 16 & 8 \\
12 & 8 & 22 & 11 & 11 \\
13 & 2 & 23 & 30 & 6 \\
14 & 4 & 25 & 15 & 15 \\
15 & 3 & 17 & 30 & 8 \\
16 & 5 & 29 & 14 & 11 \\
17 & 15 & 23 & 27 & 11 \\
18 & 12 & 26 & 33 & 12 \\
19 & 8 & 16 & 34 & 16 \\
20 & 2 & & 25 & \\
\hline \hline
\end{tabular}

\section{DATA ANALYSIS}

To test the hypothesis that the 2 measures of heterogeneity could lead to different assessments of species richness, we ran a multiple regression test utilizing the following factors: habitat heterogeneity (number of different types of substrate), habitat amount (number of boxes), and abundance of individuals (log transformed). The dependent variable was morphospecies richness (SPSS Statistics, version 17.0, Polar Engineering and Consulting, Nikiski, Alaska, USA). We included the abundance of individuals as the third factor to remove the random placement effect. We transformed this axis because we expected to find an exponential relationship between the abundance of individuals and species richness.

We ran a Mantel correlation test to determine if similar sets of substrates attracted similar sets of morphospecies. Two distance matrices were built based on absolute Euclidian distance. One matrix used the distances between artificial environments in terms of the presence and absence of arthropod morphospecies, while the other matrix used the distances between artificial environments in terms of the presence and absence of substrates. The significance of the correlation coefficient was assessed by a randomization test with 10000 permutations in the R software (version 2.12.1), vegan package (Oksanen et al., 2008).

We adopted 0.05 as the significance level for all analyses and checked the partial graphs of the multiple regression to evaluate the premises of the test and the partial influence of each factor on the dependent variable.

\section{Results}

We sampled 577 arthropods belonging to 64 morphospecies, 18 orders, and 4 different classes: Arachnida, Crustaceae, Hexapoda, and Myriapoda (Table III). Araneae was the order with the greatest number of individuals (30.7\% of the total) and morphospecies $(21.9 \%$ of the total). Some usually abundant groups (Gibb \& Oseto, 2006)

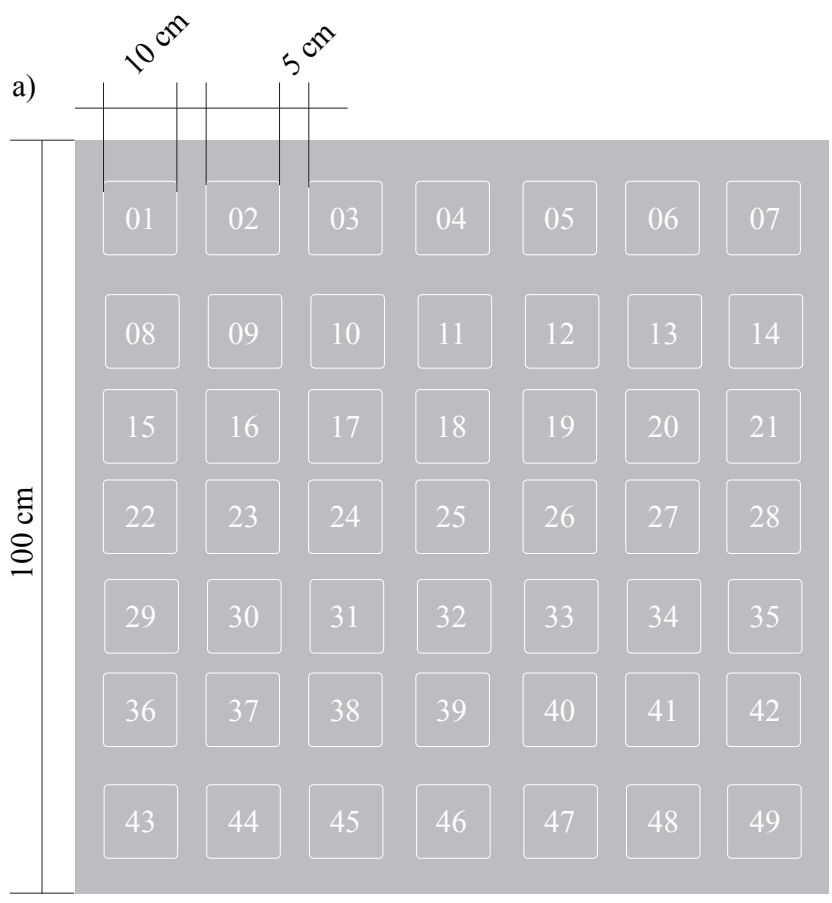

b)

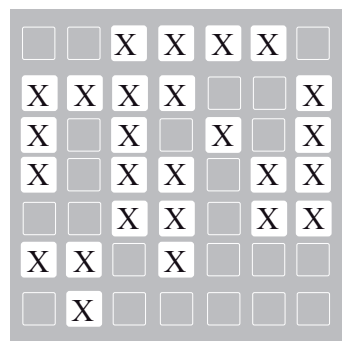

c)

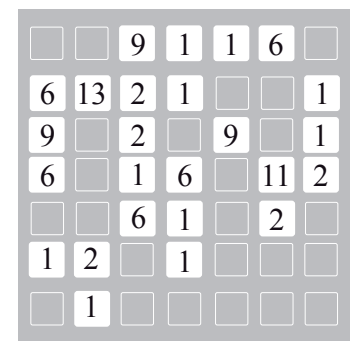

Figure 1. Example of the content and construction of an artificial habitat. We created 49 slots in which to place the boxes. These slots were $10 \mathrm{~cm}$ wide and spaced $5 \mathrm{~cm}$ from each other as depicted in a). We selected a random number of boxes between 21 and 40 to attach to the artificial environment randomly as depicted in b) by the ' $x$ '. This example used the number 25 . We then selected the richness of substrates by choosing a number between 1 and 19 ( 5 in the example). With 5 selected as habitat heterogeneity and 25 as habitat amount, we determined the type of substrates to use in this habitat (types 2, 6, 9, 11, and 13 in the example) and then filled the empty boxes with the substrates selected as depicted in c).

were observed at a very low abundance and low richness. For example, only 3 specimens (2 morphospecies) of Coleoptera and 5 specimens (1 morphospecies) of Diplopoda were observed (Table III). As expected, the total abundance of arthropods observed was very low compared to passive trapping and luring methods (e.g., Longino, 1994; Holland \& Smith, 1999; Edwards \& Thornton, 2001; Kitching, Li \& Stork, 2001; Work et al., 2002). Compared with other studies that used the colonization of newly built structures as the sampling method, our study abundance was not low (e.g., Bowie \& Frampton, 2004; Bowie et al., 2006; Hodge et al., 2007).

Preferential colonization of a specific substrate type was not observed in any arthropod group, and no substrate type remained unoccupied during the entire experiment. The primary data used in the analysis are presented in Table II. 
The multiple regression test indicated that neither habitat heterogeneity nor habitat amount was significantly correlated with arthropod morphospecies richness, but the abundance of individuals was significantly correlated. The multiple regression general model was significant $\left(F_{3,16}=13.950, P<0.000, r^{2}=0.723\right)$. The partial regression with habitat heterogeneity was not significant $\left(t=-1.762, P=0.097, r^{2}=0.162\right)$, nor was the partial regression with habitat amount $(t=0.981, P=0.341$, $\left.r^{2}=0.057\right)$. The partial effect of abundance of individuals was significant, linear, and positive $(t=5.341, P<0.001$, $r^{2}=0.641$ ) (Figure 2). The assumptions of the tests we ran were met: a) there was no correlation between the values of habitat heterogeneity, habitat amount, and individual abundance (tolerance level was $0.873,0.744$, and 0.735 , respectively); b) Shapiro-Wilk normality tests indicated that the distributions of residuals were normal $\left(W_{20}=0.944\right.$, $P=0.281$ ); and c) partial regression plot assessment indicated that the relationships were linear, and that the mean size of residuals was not related to the factors.

We found no apparent association between the sets of substrate types and the sets of arthropod morphospecies. The Mantel test did not indicate a correlation between the matrix for presence and absence of arthropods and the matrix for presence and absence of substrates in the artificial habitats $\left(r_{\mathrm{m}}=0.033, P=0.214\right)$.

\section{Discussion}

In this study, we argue that conceptions of heterogeneity can influence assessment of the environmental heterogeneity model. Our results show that neither habitat amount nor habitat heterogeneity had a significant relationship with species richness when the effect of random sample was removed. Moreover, we found no association between the composition of arthropods and the occurrence of substrates at this scale.

Kallimanis et al. (2008) suggest that the effect of habitat amount on species richness at fine spatial scales

TABLE III. Abundance and relative abundance of all order of arthropods observed in all artificial habitats.

\begin{tabular}{lrrcc}
\hline \hline Order & Abundance & $\begin{array}{c}\text { Abundance } \\
(\%)\end{array}$ & $\begin{array}{c}\text { Morphospecies } \\
\text { richness }\end{array}$ & $\begin{array}{c}\text { Morphospecies } \\
\text { richness (\%) }\end{array}$ \\
\hline Araneae & 177 & 30.7 & 14 & 21.9 \\
Blattodea & 32 & 5.5 & 1 & 1.6 \\
Coleoptera & 3 & 0.5 & 2 & 3.1 \\
Collembola & 160 & 27.7 & 8 & 12.5 \\
Diplopoda & 5 & 0.9 & 1 & 1.6 \\
Diptera & 12 & 2.1 & 5 & 7.8 \\
Hemiptera & 5 & 0.9 & 2 & 3.1 \\
Hymenoptera & 21 & 3.6 & 7 & 10.9 \\
Isopoda & 85 & 14.7 & 1 & 1.6 \\
Isoptera & 2 & 0.3 & 2 & 3.1 \\
Mantodea & 2 & 0.3 & 2 & 3.1 \\
Orthoptera & 17 & 2.9 & 6 & 9.4 \\
Parasitiformes & 31 & 5.4 & 7 & 1.6 \\
Pseudoscorpionida & 9 & 1.6 & 1 & 1.6 \\
Psocoptera & 5 & 0.9 & 1 & 1.6 \\
Symphila & 7 & 1.2 & 1 & 1.6 \\
Thysanoptera & 1 & 0.2 & 1 & 3.1 \\
Thysanura & 3 & 0.5 & 2 & 100.0 \\
TOTAL & 577 & 100.0 & 64 & \\
\hline \hline
\end{tabular}

is due solely to the increase in the number of individuals and the random sample effect. The effect of habitat amount on species richness at larger spatial scales can be explained independently of the random sample effect. For large spatial scales, we expect that the habitat amount will affect population demography features that impact the probability of species extinction by
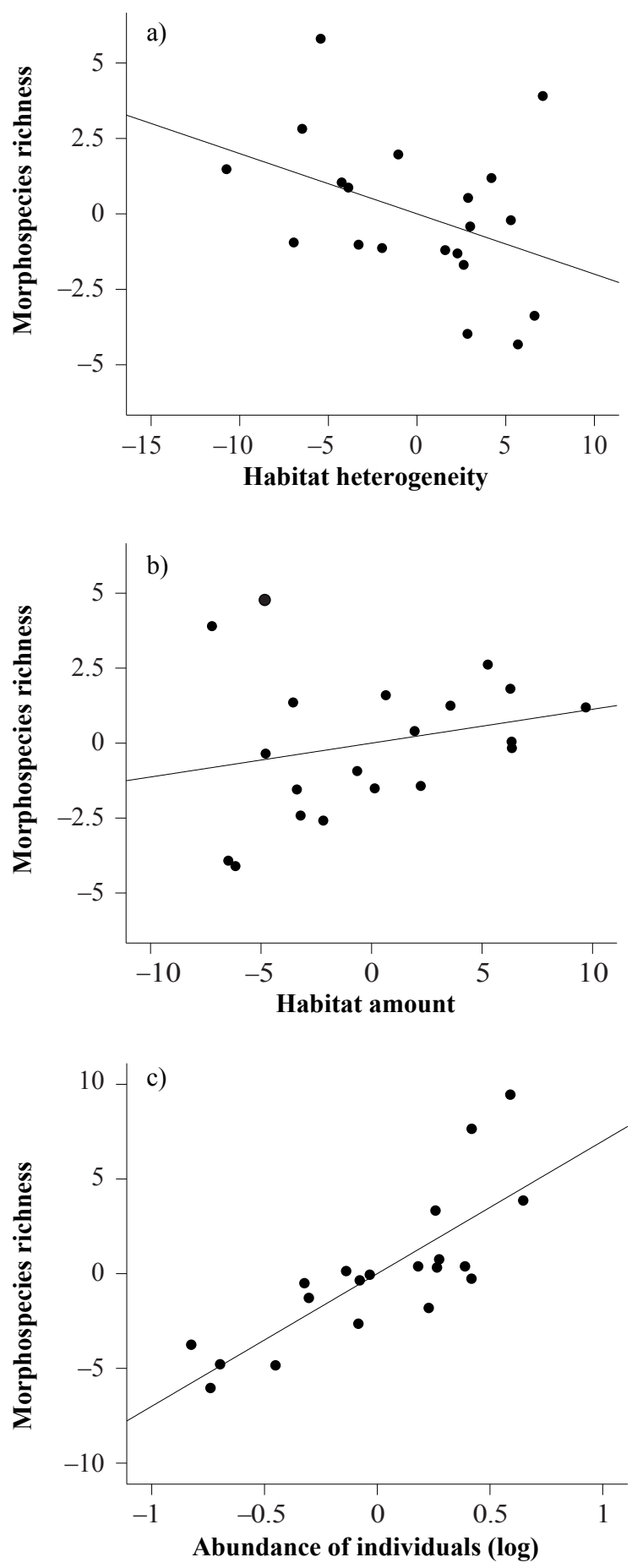

Figure 2. Graphs of the partial regression showing that neither habitat heterogeneity (a) nor habitat mouth (b) had effect on the number of morphospecies collected in the artificial habitats, whereas abundance of individuals has a strong positive effect (c). 
stochasticity (MacArthur \& Wilson, 1967; Whittaker, 1998; Kallimanis et al., 2008). The scale used in our experiment was too fine to expect effects of the demographic process on arthropod distribution, and we did not expect that the environment with higher values of habitat amount would have populations with less chance of extinction. The only expected effect of habitat amount on arthropod morphospecies richness for this scale was the effect of the number of individuals (random placement hypothesis). Once we removed the effect of abundance, we observed no influence of habitat amount on species richness. This finding was expected; most studies evaluating the model of heterogeneity used habitat amount as a fine-scale measurement (e.g., Heck \& Wetstone, 1977; Halaj, Ross \& Moldenke, 2000; Schiegg, 2000).

Some relevant papers have discussed the effect of area on species richness (e.g., MacArthur \& Wilson, 1967; Triantis et al., 2003). However, recent studies have indicated that area per se fails to explain species richness when dissociated from heterogeneity (Báldi, 2008; Shi et al., 2010) because these variables in nature are always correlated (MacArthur \& Wilson, 1967; Rosenzweig, 1995; Mac Nally \& Watson, 1997). Kallimanis et al. (2008) demonstrated that habitat amount can affect species richness when dissociated from habitat heterogeneity for coarse scales. Our present study shows that the random placement effect potentially explains the habitat amount effect for fine spatial scales.

We did not observe a statistically significant effect for habitat heterogeneity on species richness either when we controlled or when we did not control arthropod abundance. Furthermore, several pieces of evidence suggest that specific arthropod morphospecies did not associate with specific substrate types in the artificial environments. The same species were found in boxes with different types of substrates, and different species were found in boxes with the same type of substrate. The Mantel correlation test showed that artificial habitats with similar substrates did not attract similar sets of arthropod morphospecies. The number of structure types was not significantly related to morphospecies richness in the artificial environments, even though the different substrate types represented structures important to arthropod ecology and presented different types of shelter and nesting places with different humidity levels, luminosity levels, and structural arrangements. We expected that environments with a greater diversity of features would sustain a higher number of arthropods species and/or that different combinations of features would favour different sets of arthropods species, but neither of these outcomes happened. The outcome observed in this study would be expected if the resources offered by the artificial substrates were abundant enough to obviate competition between the individuals of different species and permit their coexistence in artificial habitats. Instead of competing to exploit these resources, species in this scenario would potentially explore new environments. This scenario suggests that a larger number of habitats in one of our artificial environments should increase the probability that a new species would explore this environment and boost environmental species richness through the random sample effect.
The model of habitat heterogeneity is theoretically independent of individual abundance, and we did not expect that the statistical removal of the effect of abundance would change the relationship between species richness and heterogeneity (MacArthur \& MacArthur, 1961). We anticipated that the random sample effect would primarily influence habitat amount for the fine spatial scale (Kallimanis et al., 2007) and that we would observe no effect of habitat amount on species richness if we removed the abundance effect of individuals. Our study tested and corroborated this hypothesis. At coarse scales, the effect of area per se is not necessarily dependent on the abundance of individuals, because the greater richness in larger areas at this scale could be related to more complex population dynamics, with the random placement effect playing a more minor role. However, this hypothesis has not been tested.

Our results suggest that these 2 aspects of heterogeneity represent 2 distinct features of an environment and use different mechanisms to affect species richness. For fine spatial scales, an increase in the number of different structures may not represent a linear increase in a new niche dimension, resulting in a lack of influence by heterogeneity. Habitat amount may explain many of the positive relationships observed in the literature (e.g., Pianka, 1966; August, 1983; Böhning-Gaese, 1997; Randlkofer et al., 2010), including the example in MacArthur and MacArthur (1961). Almost none of these authors isolated the effects of habitat amount and habitat heterogeneity to test their separate roles, even though these variables tend to be correlated in natural environments. This finding suggests that more studies similar to ours are required to better isolate the effects of habitat amount and habitat heterogeneity on species diversity. We agree with those authors who argue that the model of heterogeneity and the area per se hypothesis are complementary in explaining variation in species richness through different environments (Ricklefs \& Lovette, 1999; Pysek, Kucera \& Jarosik, 2002; Kallimanis et al., 2008; Marini et al., 2010). Kallimanis et al. (2008) argue that the most important influence of heterogeneity is to increase the slope of the species-area relationship, which might change according to scale. We observed that the partial effect of habitat heterogeneity may not be very important at fine spatial scales because the individuals of this very diverse community may not be perceiving heterogeneity as measured. We also observed that the random sampling phenomenon alone explains the effect of habitat amount. We encourage further study to test the partial effects of habitat amount, heterogeneity, and random sampling on species richness on a broader scale.

\section{Acknowledgements}

We thank A. Mendonça, B. Brito, N. Santos, R. Alves, and S. C. Rocha for their help during our fieldwork and the Laboratório de Vertebrados Terrestres team for their support throughout the project. We are indebted to A. Brescovit and the Laboratório de Artrópodes of Butantan Institute for spider identification. We thank E. M. Neto and M. Nogueira for their corrections and suggestions. B. Travassos-de-Britto and P. L. B. da Rocha were supported by scholarships from the Fundação de Amparo à Pesquisa do Estado da Bahia (FAPESB) and Conselho Nacional de Desenvolvimento Científico e Tecnológico (CNPq) during this project. 


\section{Literature cited}

Antvogel, H. \& A. Bonn, 2001. Environmental parameters and microspatial distribution of insects: A case study of carabids in an alluvial forest. Ecography, 24: 470-482.

Atauri, J. A. \& J. V. Lucio, 2001. The role of landscape structure in species richness distribution of birds, amphibians, reptiles and lepidopterans in Mediterranean landscapes. Landscape Ecology, 16: 147-159.

August, P. V., 1983. The role of habitat complexity and heterogeneity in structuring tropical mammal communities. Ecology, 64: $1495-1507$.

Báldi, A., 2008. Habitat heterogeneity overrides the species-area relationship. Journal of Biogeography, 35: 675-681.

Bess, E. C., R. R. Parmentar, S. McCoy \& M. C. Molles Jr, 2002. Responses of a riparian forest-floor arthropod community to wildfire in the middle Rio Grande Valley, New Mexico. Entomological Society of America, 31: 774-784.

Blaum, N., C. Seymour, E. Rossmanith, M. Schwager \& F. Jeltsch, 2009. Changes in arthropod diversity along a land use driven gradient of shrub cover in savannah rangelands: Identification of suitable indicators. Biodiversity and Conservation, 18: $1187-1199$.

Böhning-Gaese, K., 1997. Determinants of avian species richness at different spatial scales. Journal of Biogeography, 24: 49-60.

Bowie, M. H. \& C. M. Frampton, 2004. A practical technique for non-destructive monitoring of soil surface invertebrates for ecological restoration programmes. Ecological Management and Restoration, 5: 34-42.

Bowie, M. H., S. Hodge, J. C. Banks \& C. J. Vink, 2006. An appraisal of simple tree-mounted shelters for non-lethal monitoring of weta (Orthoptera: Anostosmatidae and Rhaphidophoridae) in New Zealand nature reserves. Journal of Insect Conservation, 10: 261-268.

Brose, U., 2003. Regional diversity of temporary wetland carabid beetle communities: A matter of landscape features or cultivation intensity? Agriculture Ecosystems and Environment, 98: 163-167.

Ceballos, G., J. Pacheco \& R. List, 1999. Influence of prairie dogs (Cynomys ludovicianus) on habitat heterogeneity and mammalian diversity in Mexico. Journal of Arid Environments, 41: 161-172.

Connor, E. F. \& E. D. McCoy, 1979. The statistics and biology of the species-area relationship. American Naturalist, 113: 791-833.

Derraik, J. G. B., G. P. Closs, K. J. M. Dickinson, P. Sirvid, B. I. P. Barratt \& B. H. Patrick, 2002. Arthropod morphospecies versus taxonomic species: A case study with Araneae, Coleoptera, and Lepidoptera. Conservation Biology, 16: 1015-1023.

Edwards, J. S. \& W. B. Thornton, 2001. Colonization of an island volcano, Long Island, Papua New Guinea, and an emergent island, Motmot, in its caldera lake. VI. The pioneer arthropod community of Motmot. Journal of Biogeography, 28: $1379-1388$.

Feller, I. C. \& W. N. Mathis, 1997. Primary herbivory by woodboring insects along an architectural gradient of Rhizophora mangle. Biotropica, 29: 440-451.

Gibb, T. \& C. Oseto, 2006. Arthropod Collection and Identification: Field and Laboratory Techniques. Academic Press, San Diego, California.

González-Megías, A., J. M. Gómez \& F. Sánchez-Piñero, 2011. Spatio-temporal change in the relationship between habitat heterogeneity and species diversity. Acta Oecologica, 37: 179-186.
Gürtler, R. E., G. M. Vazquez Prokopec, L. A. Ceballos, C. Lund Petersen \& O. D. Salomon, 2001. Comparison between two artificial shelter units and timed manual collections for detecting peridomestic Triantoma infestans (Hemiptera: Redvuiidae) in rural northwestern Argentina. Journal of Medical Entomology, 38: 429-436.

Halaj, J., D. W. Ross \& A. R. Moldenke, 2000. Importance of habitat structure to the arthropod food-web in Douglas-fir canopies. Oikos, 90: 139-152.

Heck, K. L. J. \& G. S. Wetstone, 1977. Habitat complexity and invertebrate species richness and abundance in tropical seagrass meadows. Journal of Biogeography, 4: 135-142.

Hodge, S., C. J. Vink, J. C. Banks \& M. H. Bowie, 2007. The use of tree-mounted artificial shelters to investigate arboreal spider communities in New Zealand nature reserves. Journal of Arachnology, 35: 129-136.

Holland, J. M. \& S. Smith, 1999. Sampling epigeal arthropods: An evaluation of fenced pitfall traps using mark-release-recapture and comparisons to unfenced pitfall traps in arable crops. Entomologia Experimentalis et Applicata, 9: 347-357.

Huston, M. A., 1979. General hypothesis of species diversity. American Naturalist, 113: 81-101.

Jonsson, M., G. W. Yeates \& D. A. Wardle, 2009. Patterns of invertebrate density and taxonomic richness across gradients of area, isolation, and vegetation diversity in a lake-island system. Ecography, 32: 963-972.

Kadmon, R. \& O. Allouche, 2007. Integrating the effects of area, isolation, and habitat heterogeneity on species diversity: A unification of island biogeography and niche theory. American Naturalist, 170: 443-454.

Kallimanis, A. S., A. D. Mazaris, J. Tzanopoulos, J. M. Halley, J. D. Pantis \& S. P. Sgardelis, 2008. How does habitat diversity affect the species-area relationship? Global Ecology and Biogeography, 17: 532-538.

Kaspari, M. \& M. D. Weiser, 1999. The size-grain hypothesis and interspecific scaling in ants. Functional Ecology, 13: 530-538.

Kitching, R. L., D. Li \& N. E. Stork, 2001. Assessing biodiversity 'sampling packages': How similar are arthropod assemblages in different tropical rainforest? Biodiversity and Conservation, 10: 793-813.

Kolasa, J. \& S. T. A. Pickett, 1991. The heterogeneity of heterogeneity: A glossary. Pages 1-23 in J. Kolasa \& S. T.A. Pickett (eds). Ecological Heterogeneity. Ecological Studies, 86, Springer, New York.

Kohn, D. D. \& D. M. Walsh, 1994. Plant species richness: The effect of island size and habitat diversity. Journal of Ecology, 82: $367-377$.

Lassau, S. A. \& D. F. Hochuli, 2004. Effects of habitat complexity on ant assemblages. Ecography, 27: 157-164.

Lassau, S. A., D. F. Hochuli, G. Cassis \& C. A. M. Reid, 2005. Effects of habitat complexity on forest beetle diversity: Do functional groups respond consistently? Diversity and Distributions, 11: 73-82.

Longino, J. T., 1994. How to measure arthropod diversity in a tropical rainforest. Biology International, 28: 3-13.

MacArthur, R. H. \& J. W. MacArthur, 1961. On bird species diversity. Ecology, 42: 594-598.

MacArthur, R. H. \& E. O. Wilson, 1967. The Theory of Island Biogeography. Princeton University Press, Princeton, New Jersey. 
Mac Nally, R. \& D. M. Watson, 1997. Distinguishing area and habitat heterogeneity effects on species richness: birds in Victorian buloke remnants. Austral Ecology, 22: 227-232.

Marini, L., R. Bommarco, P. Fontana \& A. Battisti, 2010. Disentangling effects of habitat diversity and area on orthopteran species with contrasting mobility. Biological Conservation, 143: 2164-2171.

McGuinness, K. A., 1984. Equations and explanations in the study of species-area curves. Biological Review, 59: 423-440.

Murdoc, W. W., F. C. Evans \& C. H. Peterson, 1972. Diversity and pattern in plants and insects. Ecology, 53: 819-829.

Myklestad, A. \& M. Saetersdal, 2004. The importance of traditional meadow management techniques for conservation of vascular plant species richness in Norway. Biological Conservation, 118: 133-139.

Nilsson, S. G., J. Bengtsson \& S. As, 1988. Habitat diversity or area per se? Species richness of woody plants, carabid beetles and land snails on islands. Journal of Animal Ecology. 57: $685-704$

Oksanen, J., R. Kindt, P. Legendre, B. O'Hara, G. L. Simpson \& M. H. H. Stevens, 2008. Vegan: Community Ecology Package. $\mathrm{R}$ package version 1.11-0. Online [URL] http://vegan.rforge.r-project.org/ (Accessed on 10 July 2013).

Oliver, I. \& A. J. Beattie, 1996a. Invertebrate morphospecies as surrogates for species: A case study. Conservation Biology, 10: 99-109.

Oliver, I. \& A. J. Beattie, 1996b. Designing a cost-effective invertebrate survey: A test of methods for rapid assessment of biodiversity. Ecological Applications, 594-607.

Pianka, E. R., 1966. Convexity, desert lizards, and spatial heterogeneity. Ecology, 44: 1055-1059.

Pik, A. J., I. Oliver \& A. J. Beattie, 1999. Taxonomic sufficiency in ecological studies of terrestrial invertebrates. Australian Journal of Ecology, 24: 555-562.

Preston, F. W., 1960. Time and space and the variation of species. Ecology, 41: 612-627.

Pysek, P., T. Kucera \& V. Jarosik, 2002. Plant species richness of nature reserves: The interplay of area, climate and habitat in a central European landscape. Global Ecology \& Biogeography, 11: 279-289.

Randlkofer, B., E. Obermaier, M. Hilker \& T. Meiners, 2010. Vegetation complexity: The influence of plant species diversity and plant structures on plant chemical complexity and arthropods. Basic and Applied Ecology, 11: 383-395.

Ricklefs, R. E. \& I. J. Lovette, 1999. The roles of island area per se and habitat diversity in the species-area relationships of four Lesser Antillean faunal groups. Journal of Animal Ecology, 68: 1142-1160.
Robinson, J. V., 1981. The effect of architectural variation in habitat on a spider community: An experimental field study. Ecology, 62: 73-80.

Rosenzweig, M. L., 1995. Species Diversity in Space and Time. Cambridge University Press, Cambridge.

Schiegg, K., 2000. Effects of dead wood volume and connectivity on saproxylic insect species diversity. Écoscience, 7: 290-298.

Schnell, M. R., A. J. Pik \& J. M. Dangerfield, 2003. Ant community succession within eucalypt plantations on used pasture and implications for taxonomic sufficiency in biomonitoring. Austral Ecology, 28: 553-565.

Shi, J., K. Ma, J. Wang, J. Zhao \& K. He, 2010. Vascular plant species richness on wetland remnants is determined by both area and habitat heterogeneity. Biodiversity and Conservation, 19: 1279-1295.

Simpson, G. G., 1964. Species density of North American recent mammals. Systematic Zoology, 57-73.

Sirami, C., P. Jay-Robert, H. Brustel, L. Valladares, S. Le Guillioux \& J. L. Martin, 2008. Saproxilic beetle assemblages of old holm-oak trees in the Mediterranean region: Role of a keystone structure in a changing heterogeneous landscape. Revue d'écologie: La Terre et la vie, 10: 101-114.

Sparrow, A. D., 1999. A heterogeneity of heterogeneities. Tree, 14: $422-423$.

Tews, J., U. Brose, V. Grimm, K. Tielbörger, M. C. Wichmann, M. Shwager \& F. Jeltsch, 2004. Animal species diversity driven by habitat heterogeneity: The importance of keystone structures. Journal of Biogeography, 31: 79-92.

Thomas, J. A., N. A. D. Bourn, R. T. Clarke, K. E. Stewart, D. J. Simcox, G. S. Pearman, R. Curtis \& B. Goodger, 2001. The quality and isolation of habitat patches both determine where butterflies persist in fragmented landscapes. Proceedings of the Royal Society B, 268: 1791-1796.

Triantis, K. A., M. Mylonas, K. Lika \& K. Vardinoyannis, 2003. A model for the species-area-habitat relationship. Journal of Biogeography, 30: 19-27.

Vivian-Smith, G., 1997. Microtopographic heterogeneity and floristic diversity in experimental wetland communities. Journal of Ecology, 85: 71-82.

Whittaker, R. J., 1998. Island Biogeography: Ecology, Evolution, and Conservation. Oxford University Press, Oxford.

Whittaker, R. J., S. A. Levin \& R. B. Root, 1973. Niche, habitat, and ecotope. American Naturalist, 107: 321-338.

Work, T. T., C. M. Buddle, L. M. Korinus \& J. R. Spence, 2002. Pitfall trap size and capture of three taxa of litterdwelling arthropods: Implications for biodiversity studies. Environmental Entomology, 31: 438-448. 